\title{
THE AUSTRALIAN CONTRIBUTION TO THE HISTORY OF THE PNEUMOCONIOSES
}

\author{
by
}

\section{BRYAN GANDEVIA}

The Australian contribution to the evolution of knowledge concerning the pneumoconioses is perhaps better known overseas than locally. In fact, these studies, commencing about the turn of the century, and dealing with epidemiology, aetiology, pathogenesis, pathology and prevention, were amongst the most systematic and comprehensive medical research undertaken in a specific field in Australia prior to the Second World War (for references, see Holster, 1970). Unfortunately, the results commonly appeared either as separate publications under government auspices or in government reports of various kinds; although the work became known to some overseas experts, its full extent and significance were probably not appreciated in Australia even at the time.

In recent years, I have tried, with no little difficulty, to acquire, in the original or in photostat, the relevant published material. It would be premature to attempt any thorough analysis of the history of the dust diseases in Australia, and to integrate the Australian work with progress abroad. As an introductory study, I propose, first, to indicate some of the steps necessary in producing such a historical analysis, taking coal and silica hazards as the classic examples. I shall pay particular attention to the problems which the historian faces in interpreting the available data and hence necessarily to the methodology of early investigators. Second, I shall briefly review several Australian studies, partly to illustrate the breadth and depth of the Australian work, and partly to indicate the significance to the historian, and the growing awareness amongst investigators, of basic principles in the epidemiological investigation of chronic diseases due to occupational hazards. The establishment of these principles is, of course, a matter of very recent history indeed, but the historian must still apply them retrospectively as a research technique within his own discipline.

\section{PROBLEMS IN THE HISTORICAL STUDY OF THE PNEUMOCONIOSES}

The first problem in studying the history of a disease, or group of diseases, is one of terminology and nosology. In modern terms, the three diseases with which we are primarily concerned are silicosis, coal worker's pneumoconiosis and tuberculosis, and it is easy enough to lay down specific environmental, radiological or bacteriological conditions which must be met before one or more of these diagnoses can be established. Modern knowledge also tells us to expect chronic bronchitis and emphysema, whether with or without pneumoconiosis. Asthma must also be added, although this might not be strictly acceptable using modern definitions, because the term covered a multitude of causes of shortness of breath over the earlier decades of the period with which we are concerned; 'miner's asthma' was a recognized diagnostic label, 


\section{The Australian Contribution to the History of the Pneumoconioses}

doubtless applied to several different pathological conditions, for many years. At the time the story begins, in the last decade of the nineteenth century, these terms were either not in use or else specific criteria for their definition and differentiation had not been defined, perhaps especially for epidemiological purposes. We must therefore look for the three 'primary' conditions under a variety of different names, of which perhaps the most vulgar was 'black spit' and perhaps the most accurate, for the earlier period, was 'miner's phthisis'. We must also look for them under what are, by modern standards, frankly erroneous diagnostic labels; miners died of 'chronic bronchitis' when in fact they died of a more specific mining hazard, a deduction legitimately based on available mortality data. In differentiating tuberculosis in the earlier period, before bacteriological examinations were applied on a large scale, we may be forced to rely on inferences based on physical signs and evidence of toxaemia. Emphysema as a primary diagnosis may, more precisely, have been a complication of pneumoconiosis, progressive massive fibrosis or chronic tuberculosis and not the essential or primary condition. In tracing the history of these diseases, we must take note of the changing terminology, of what each author meant by his own particular terms, and of what his criteria were for the labels he employed.

Second, consideration must be given to the changing natural history of the diseases in question. Here we have a more difficult problem than faces the historian of neoplastic or infectious diseases, for the natural history of the dust diseases is inevitably protracted, and their aetiology, far from being an isolated event, is a long-continued process; both pathogenesis and progression are modified by changes occurring over years in the physical environment. A change in both the prevalence and the character of miners' lung diseases may, and in fact does, reflect changes in the physical environment, although only after an appropriate time lag. Perhaps the most striking manifestation of this is the fact that no reference has yet been found in the Australian medical literature to chronic lung disease in miners until the latter part of the last decade of the nineteenth century, a decade or so after the introduction of the machine rock drill, and twenty years or more after deep mining for gold had become established. Conversely, the decline in coal worker's pneumoconiosis in New South Wales in recent years can be related to more effective dust control, perhaps especially since 1945. The natural history and the epidemiology of tuberculosis must also be taken into account. For reasons which have been discussed elsewhere (Cumpston, 1923, 1931; Holmes, 1937; Thomas and Gandevia, 1959), tuberculosis became prevalent in Australia in the last third of the nineteenth century, and its prevalence, in terms of mortality, amongst young adults was disproportionately high. Around the turn of the century, the age distribution of pulmonary tuberculosis in the community began to stabilize at more conventional levels. The gradually declining prevalence of 'open' pulmonary tuberculosis in the community as a whole over the past half century or more has probably had its effect on the disability produced by, or associated with, the pneumoconiosis of miners; it has certainly affected mortality. Exclusion of workers with tuberculosis from the mines (widely practised by 1930 , although suggested in 1906) may have been less important than its advocates anticipated, since tuberculosis particularly affected miners in the older age groups throughout the period under review. Indeed, changing habits in regard to cigarette smoking, poorly if at all 


\section{Bryan Gandevia}

documented in most studies, may well have had a greater significance in regard to respiratory symptomatology.

It follows that in evaluating the disability recorded amongst miners in various surveys over the years we are dealing with a complex of factors which were gradually but constantly changing, both absolutely and relative to one another. In part, but only in part, the diminishing importance of active tuberculosis is responsible for the gradual decline in the term 'miner's phthsis' and its replacement, more or less successively, by silico-tuberculosis, and silicosis or coal pneumoconiosis, with or without tuberculosis. By contrast, the prevalence and severity of tuberculosis in earlier years tended to overshadow the effects of pneumoconiosis alone, and hence to obscure such disability as the latter produced. Progressive massive fibrosis, an important cause of disability in pneumoconiosis due to coal or silica, was probably labelled as silicotuberculosis or miner's phthisis in former years in cases in which no tubercle bacilli were demonstrated.

The third problem is concerned with making some deductions from the available data as to the prevalence of the relevant conditions and the change in prevalence over the years, if possible in relation to the particular causal factors. This is a matter of interpretation by the historian, and it presupposes consideration of a fourth problem, namely, an examination of the methodology employed by earlier observers, particularly from the epidemiological point of view. Thus, the figures for morbidity - or mortality -from different sources cannot be accepted at face value, certainly for comparison with those of other observers at a different period or in a different geographical area. The full significance of the criteria adopted for diagnosis, of the subjective nature of many clinical criteria and of observer variation has been appreciated only in relatively recent years, when the necessity for precision in comparisons between surveys has led to quantitative investigations of these problems and to the adoption of specific measures to minimize their influence. In the past, errors due to sampling methods were not appreciated to the full. For example, the Queensland Royal Commission on the health of miners in 1911 admitted that it had examined a woefully inadequate sample (about three per cent) of the total population and acknowledged that the sample may have been influenced by the selective absence or presence of those who knew they were unhealthy. However, an appreciation of this bias did not seriously enter into the Commission's concepts of a suitable and appropriate survey, as is indicated by its suggestion that the number medically examined should be 6,000 or so. This suggestion ignores the fact that unless sources of bias are successfully countered a mere increase in numbers simply increases the error. In effect, the Commission's recognition of the sources of bias in its own survey was thrust upon it by the extremely poor response of the miners to invitations to be medically examined; it was not an indication of advanced scientific thinking in epidemiology. Nothing approaching the concept of a random sample emerges until 1948; up to that time, the aim of the more effective investigators, as judged by a modern epidemiologist, was the examination of the total population, or as close to this as possible. Systems of grading, within, for example, the diagnostic category of 'pulmonary fibrosis', also require critical examination by the historian, again especially in the light of specific research on this problem in recent years. 'Early', 'intermediate' and 'advanced' 


\section{The Australian Contribution to the History of the Pneumoconioses}

fibrosis require not merely definition on certain criteria, but also validation in some preferably independent way. It is not always possible to accept the gradings of early observers, and hence to compare their results with the findings of others. Without wishing to labour a question which cannot be resolved in retrospect, I might point out that the use of the terms 'early' and 'advanced' implies some confusion of duration and extent, or severity, a fallacy in grading systems, or in the use of words, which is still commonly encountered.

If the historian can be satisfied as to the validity of the basic data supplied in early studies, he may be able to analyse the results using modern statistical methods, or he may employ these methods for comparisons between surveys. I hope to adopt this approach at some future date; Outhred and his colleagues (see below) have done so over a limited period. Perhaps this approach may remind historians that they need not be confined to mere note-taking in their researches; they may with profit re-use the data they find, or even repeat, under identical conditions, the experiments of yesteryear. Incidentally, by contrast with their uncertainty in handling data concerned with the prevalence of a chronic disorder in an occupational environment, earlier investigators were very familiar, as a result of accumulated experience with infectious diseases, with the information to be gained from the age distribution of mortality. Valuable use was made of graphs of this type, in spite of difficulties arising from lack of knowledge of the population at risk in each age group.

A fifth aspect which the historian must consider is the changing attitudes towards dust control on the part of management and of employees, to the methods by which dust concentrations were measured, and to the changing standards, legal or otherwise, of acceptable limits for dust levels. These considerations have to be related to concepts of pathogenesis, which have also changed. Early in this century, the pathogenicity of silica dust was regarded as due to its physical properties of hardness, irregularity of shape and sharpness of edges and points. There was at first little or no concept of a dose-response relationship; the prevalence of disease or disability was not related so much to years of exposure as to years of age. The concept of 'dust-years' (average concentration times duration of exposure) is, of course, too modern to expect that, even fortuitously, relevant data may have been recorded. Disability was understandably equated much more with the development of complicating tuberculosis than with pneumoconiosis by itself, a view which virtually rendered any examination of 'dose-response' relationships superfluous. In addition, insofar as coal miners were concerned, there was some doubt until relatively recent years as to whether coal dust was pathogenic at all, so that the emphasis was again directed more towards tuberculosis than towards dust as the cause of disability. The influence these views might have on preventive measures is evident: exclusion of tuberculous subjects might be expected to take precedence over dust control measures. Although overall it probably did not do so, at least as judged by recommendations of various authoritative bodies, these views inevitably influenced individual miners and mine managers in their attitudes to dust control measures.

At a more fundamental level, any review of the measures adopted for the control of the dust diseases must involve an examination of the attitudes of the medical profession, and more particularly of society, to occupational diseases, and to the 


\section{Bryan Gandevia}

preservation of health and the care of the sick in general. Broadly speaking, the result of these attitudes is legislation of various kinds, conventionally used as landmarks in the history of occupational diseases. Frequently, of course, medical surveys formed part of investigations instituted by a governmental authority, which led ultimately to legislation bearing upon prevention, medical surveillance and workmen's compensation. These aspects of the Australian scene have been examined by several authors (Moore, 1930; George, 1953; A. Cumpston, 1968).

The historian's last problem is to correlate local progress with advances abroad, and to determine in what respects significant local contributions were made to world understanding, or to what extent local practice lagged behind that of overseas. I do not propose to examine these questions in this paper, although it may be noted that (i) the work of Summons (1907) received some international recognition as a very early contribution to the hazards of goldminers; (ii) the work of Nelson (1926) deserved wider recognition, but probably did not obtain it because it was not published in appropriate journals, and (iii) the work of Charles Badham in the 1920s and 1930s contributed significantly to the appreciation of the hazards of pneumoconiosis in coalminers and workers employed in tunnelling and rock drilling in several non-mining occupations. As a generalization, Australia more than kept up with, and made some contributions to, British and South African practice and research; these three countries had done more fundamental work and produced more effective social and preventive legislation than other countries up to very recent times. Relevant historical reviews include those of Fletcher (1948), Meiklejohn (1952), Gilson and Hugh-Jones (1955), Hunter (1955) and Orenstein (1957).

\section{SOME ILLUSTRATIVE INVESTIGATIONS}

In reviewing briefly several studies of interest, I shall not place much emphasis on the results obtained, but rather I shall draw attention to the methodology employed, for two reasons. First, it enables us to decide precisely what weight may be given to the figures of one observer by comparison with those of another, whether in the same or different place or period. The second reason, which is relatively independent, is that this approach reveals the evolution of a scientific approach to the epidemiology of chronic disease in an occupational context. It cannot be too emphatically stated that one is not looking back at this earlier work with the object of subjecting it to harsh criticism based upon the knowledge accumulated in recent years. Equally, one is not trying to credit early observers with a degree of foresight and understanding which they could not possibly possess. What must be done is to employ the legitimate historical technique of critically evaluating the source material before proceeding, on some other occasion, to an interpretation of its full meaning, and placing it in perspective in relation to research abroad. It may well be that work which was invaluable at the time, and conducted consistent with the knowledge of the time, could prove of little value to the historian; conversely, and perhaps mainly by good chance, a naive or scientifically unsound approach occasionally provided material of lasting significance.

Perhaps I may mention first an investigation which must surely have been done but which has never been reported. In 1852, John Hutchinson (1811-1862), who first 


\section{The Australian Contribution to the History of the Pneumoconioses}

introduced the spirometer and the term 'vital capacity', and who carried out over three thousand spirometric examinations in London, took up residence in Bendigo (then Sandhurst) on account of pulmonary tuberculosis. A frequent visitor to English mines near his birthplace at Newcastle upon Tyne in his youth, he became an expert in the geology of the Bendigo district before he left there in 1861 to die in the Fiji Islands. It seems almost beyond belief that this distinguished and original chest physician should have come to this country to a mining district and left behind him virtually no trace of professional activity, yet such seems to be the case. He was, incidentally, a gifted violinist, draughtsman, sculptor and oil painter.

In 1902, B. Stewart Cowen, practising at Eaglehawk, Victoria, drew attention to the mortality from tuberculosis in the local mining community, particularly amongst middle-aged males. Shortly afterwards, a series of articles appeared in the Bendigo Advertiser in which Dr. Cowen's views received the general support of his colleagues. These articles were reprinted by the Advertiser as a pamphlet entitled Miner's Complaint: The Primary Cause: How It May Be Combatted (1903), and distributed free to the miners of the Bendigo district.

Public interest led the Trustees of the Edward Wilson estate to seek Dr. R. R. Stawell's advice as to a young graduate who might investigate the problem, and Walter Summons (1881-1970), a Melbourne graduate of 1904, was recommended. His report (Summons, 1907) was issued in two parts, one chiefly concerned with the prevalence and causation of miner's phthisis, and one dealing impressively with the question of mine ventilation. The epidemiological content is essentially a statistical analysis of mortality amongst Bendigo miners between 1875 and 1906 . Over this period mortality rates from miner's phthisis nearly trebled (to 130 per 10,000 miners), whilst those from chronic bronchitis increased fourfold; mortality from phthisis in Melbourne and in Victoria generally had steadily declined. The age distribution of deaths from phthisis in miners and non-miners in Bendigo shows major differences (Figure 1), as Cowen had found; Summons regarded the peak in middle-age as occupationally determined, but offered no explanation for the relatively low mortality in the young miners (we may guess, of course, as he possibly did, that those with a 'hereditary predisposition' to phthisis did not take to this arduous occupation). Arguing partly from the similarity of the age distribution of deaths from phthisis and bronchitis in miners (Figure 1), and partly from his clinical experience, Summons concluded that 'bronchitis' was in fact tuberculosis.

There is no hint of any attempt at an epidemiological approach to the clinical examination of 192 miners obtained from various sources, but the clinical descriptions are excellent. Three cases of advanced disease were examined with the fluoroscopic screen through the courtesy of Dr. H. E. Jackson of Bendigo: 'between the dark patches were large areas suggesting emphysematous changes in parts of the lungs not so densely fibroid'. He examined specimens from nineteen autopsies; including these with the clinical cases in which sputum examinations for tubercle bacilli were done, he found evidence of active tuberculosis in almost half. He concluded that tuberculosis was almost always the cause of death. He clearly differentiated two types of disease on clinical and pathological grounds. The first, of 'pure fibrosis', characterized by dyspnoea of varying severity with or without productive cough and wheezing, was 'a 


\section{Bryan Gandevia}

W. SUMMONS. MORTALITY- PHTHISIS IMINERS \& NONMINERS) \& CHRONIC BRONCHITIS. BENDIGO 1875-1906.

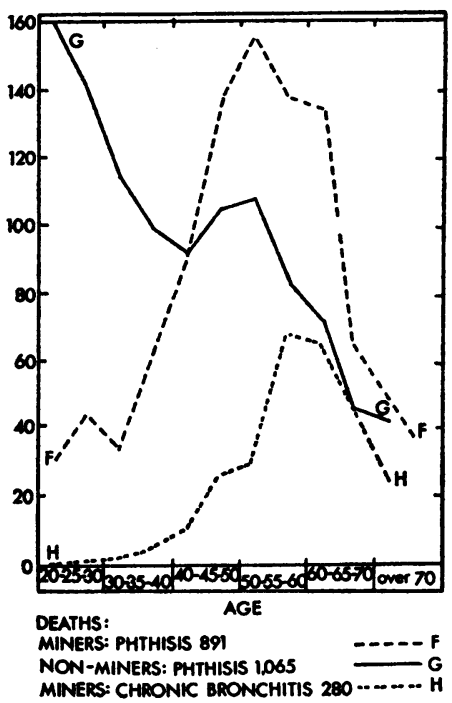

Figure 1

A composite graph, redrawn from figures in Summons (1907).
MTAL CAPACITIES

COMPARISON BETWEEN OBSERVED AND THOSE CALCU LATED FROM HEIGHT.

PERCENTAGe Of OASERVED Percentace OF OBSERVED

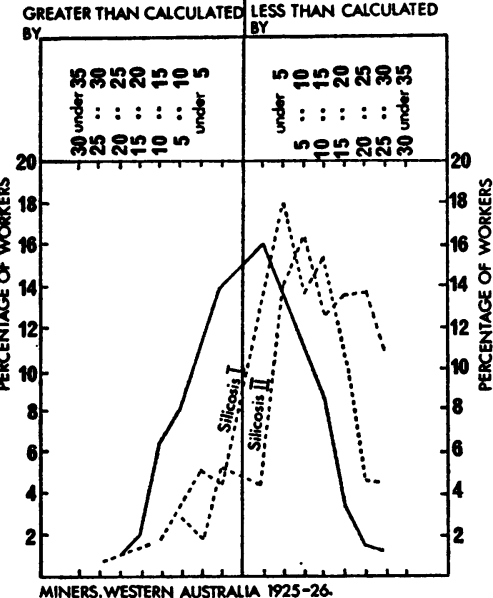

Figure 3

Redrawn from Nelson (1926)

silicosis', specifically attributable to the quartz dust and showing characteristic histological changes. The second was due to the development of active tuberculosis in an already fibroid lung, characterized clinically essentially by manifestations of toxaemia as well as by exacerbation of respiratory symptoms and signs. These unequivocal conclusions, accurate today, were a triumph for the clinicopathological method of research evolved in the preceding century. Similarly clear distinctions were not drawn in much of the work done by later investigators. In his report on the ventilation of mines he asserts that 'without dust inhalation there would be no lung disease peculiar to miners', although some liability to tuberculosis might remain; this view again was not uniformly accepted.

In a lecture given in 1914, J. W. Barrett (1918) observed: 'It may be justly said that modern curative medicine approaches the ridiculous in its organisation. I notice, for example, that the Government is proposing to give financial help to those who suffer from miner's disease. Yet Dr. Summons some time ago showed how miner's disease could be prevented. Dr. Summons had $£ 400$ placed at his disposal for the purpose of conducting his investigations. . . . Had the $f 400$ been devoted to the relief of the sufferers, it perhaps would have been of some service, but it would soon have disappeared.'

Modern industry, with its modern hazards, still needs to be reminded of Sir James' message that research offers a fundamentally more humanitarian approach than the consolation of workers' compensation.

J. H. L. Cumpston (1880-1954), as sole commissioner, was responsible for the report of a Royal Commission on Pulmonary Diseases amongst Miners in Western 


\section{The Australian Contribution to the History of the Pneumoconioses}

Australia which appeared in 1911. He examined local mortality data for the preceding decade with care, noting in particular the rising mortality rate from pulmonary tuberculosis in miners (from 8 to 31 deaths per 10,000 living miners), whilst the rate in male non-miners over the same period remained more or less constant at about 10 per 10,000 . The clinical section of the report is curiously uneven. Although the criteria used for the diagnosis and grading of fibrosis are described in considerable detail, the criteria for the diagnosis of tuberculosis are scarcely mentioned; when they are, they appear to be arbitrary and largely subjective. Von Pirquet tests and sputum microscopy were used in an unspecified number of cases, but were not required to be positive, and the results are not stated. Although aware of certain gross factors (such as illness leading to hospitalization or migration) as influencing the population available for study, he pays little heed to possible sampling errors in describing the results of examination of about 22 per cent of some 6,000 miners, or 37 per cent of the underground miners. In fact, he states that he attaches little significance to the precise 'percentages' in various categories, failing to appreciate the varied purposes for which accurate prevalence data may be used. Methodology, as much as differences in data and interpretation, was responsible for some of the differing opinions of Cumpston and Summons. Cumpston concluded that tuberculosis, as an infectious disease, was non-occupational and thus more or less coincidental, dust inhalation playing only a minor role. For this and other reasons, he stressed the distinction between fibrosis, due to dust, and tuberculosis, due to an infection, and hence took the strongest exception to the term 'miner's phthisis', which tended to relate or associate the two. However, in spite of its own Royal Commissioner, the Western Australian Government eventually passed the Miner's Phthisis Act in 1922.

The third part of Cumpston's report, 'Experimental and Pathological', forms the most interesting and original feature of his report, and is a tribute to his initiative and resource. In his own words: 'The later stages of the disease [fibrosis] are therefore clearly understood and all that is necessary is a comprehension of the earlier and intermediate stage. No reference could be found which threw any light on the pathology of these earlier stages and therefore an attempt was made to obtain some information experimentally. The methods used and the results obtained will now be described. In setting out these results, the restricted scope of the experiments and the limitations of the deductions are fully realised, and an endeavour will be made to keep within the bounds of legitimate deduction.' He then described dust inhalation experiments on several rabbits and guinea pigs, notably a relatively long-term study in which a rabbit was exposed daily for fifteen minutes to 100 -mesh quartz dust for two months and killed five months later. The pathological descriptions, notably of the migration of dust-laden phagocytes to establish peribronchiolar dust accumulations in and around lymphatics, are most impressive. Cumpston also trapped mice and cockroaches in one mine with the object of looking for tubercle bacilli in the mine dust as a potential source of human infection; perhaps he has the distinction of being the first to describe pneumoconiosis in mice. By inference from passim statements and from legends to the excellent photomicrographs, Cumpston distinguished the simple dust aggregates of coal dust inhalation from the fibrotic dust nodules induced by quartz. 


\section{Bryan Gandevia}

The first systematic use of chest radiography as a diagnostic measure in an Australian epidemiological survey was undertaken by a technical commission of inquiry into 'the prevalence of miner's phthisis and pneumoconiosis in the metalliferous mines at Broken Hill'; the report was published in Sydney in 1921. The Commission, under the chairmanship of Professor H. G. Chapman, and including Dr. W. A. Edwards as an expert in radiology, examined approximately 4,000 miners using two $\mathrm{X}$-ray machines for which a special power supply had to be installed. It is of interest today to read that it was found 'most efficient and expeditious' to have the patient standing, that the most satisfactory view was the 'dorso-ventral', and that superimposition of scapular shadows could be avoided by appropriate positioning of the arms. Largely on the basis of these glass-plate radiographs, the Commission established that pneumoconiosis, albeit of a relatively benign form, did occur in workers with no mining experience outside Broken Hill.

One of the medical examiners employed was a recent Sydney graduate, W. T. Nelson (1896-1955) (Figure 2), who, in 1925-26, proceeded to conduct the most comprehensive and effective survey to be carried out in Australia for more than another quarter of a century and probably the most thorough survey in the world prior to the 1930s. Nelson's work under the auspices of the Western Australian Government and the Commonwealth Department of Health (of which Cumpston had become Director), was aimed at detecting all miners in Western Australia with silicosis or tuberculosis, and to this end a 'health laboratory' was set up in Kalgoorlie. Portable X-ray apparatus and other equipment were taken by motor car over an area extending north to Wiluna and Meekatharra and north-west to Geraldton, thus enabling Nelson to study the entire mining population of over 4,000 men. Some of the radiographs, of good quality, survive, as do the case history sheets.

The survey is remarkable for many reasons. It recorded the prevalence of certain symptoms, such as dyspnoea, cough and sputum, rather than simply final diagnoses, in miners with and without radiographic evidence of pneumoconiosis. Its approach to the presentation and statistical analysis of the data was surprisingly modern. The diagnostic criteria were clearly defined. Nelson's clinical and radiological acumen enabled him to draw specific attention to the condition now known as progressive massive fibrosis, noting that it was not attributable to active tuberculosis and that physical signs might be absent.

Nelson's assessment of pulmonary function was far in advance of its time. In addition to vital capacity measured with a wet spirometer, breath-holding time, expiratory and inspiratory 'force', chest expansion and circumference at various levels, and exercise performance were all estimated. The exercise test required that 6-lb. dumbells be swung from the toes upward to full arm's length above the head 30 times in 80 seconds; observations were made on the development of dyspnoea and cardiac murmurs, and on the recovery time in terms of the pulse rate. Such data were unique amongst workers exposed to silica, and indeed probably so in relation to any occupational group for another decade or so.

Nelson found that vital capacity (expressed as a percentage of the predicted normal values) fell from 99 per cent in normal subjects to 93 per cent, 89 per cent and 83 per cent with advancing radiological grades of dust disease, and to 66 per cent in subjects 


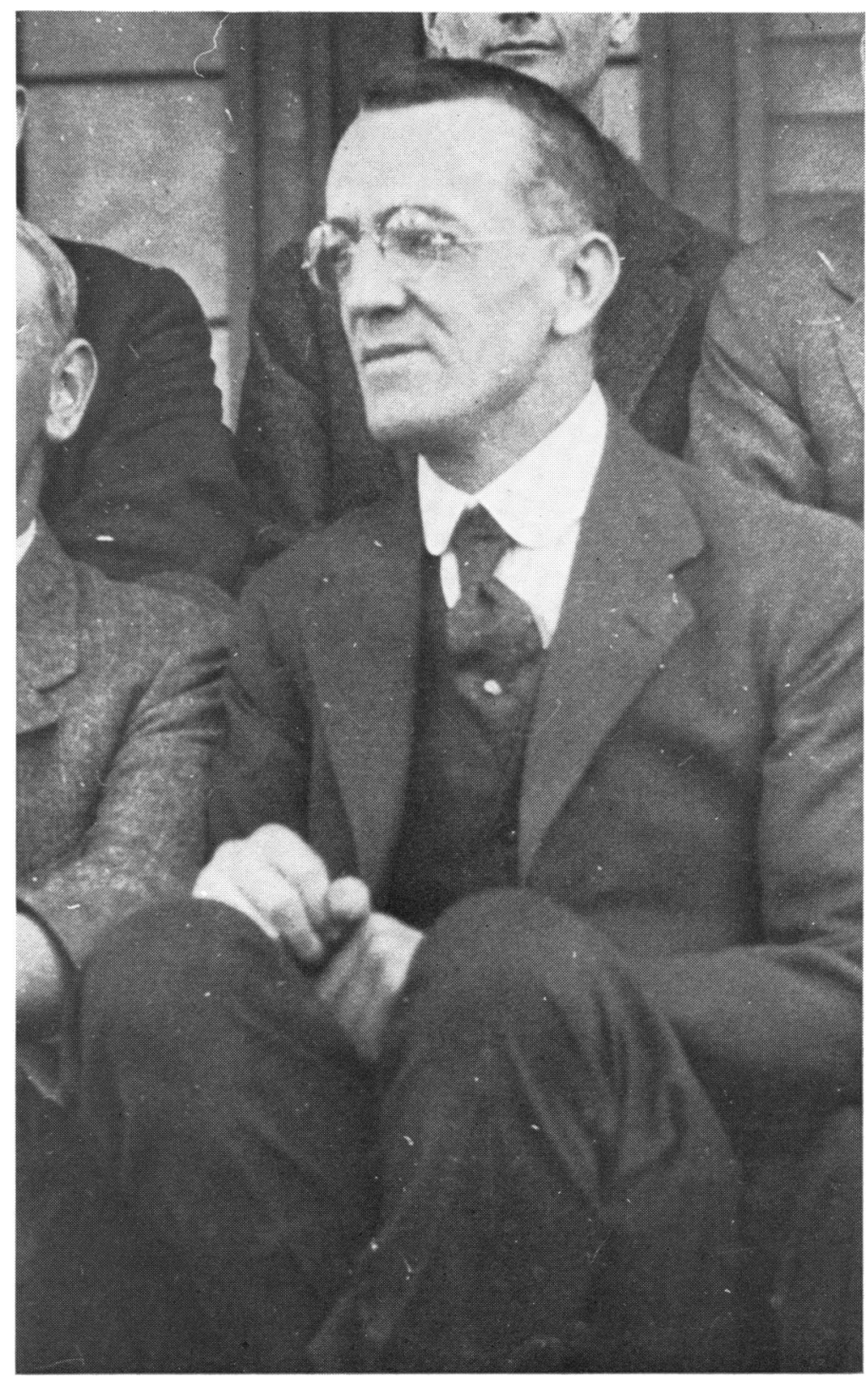

Figure 2

W. T. Nelson 


\section{The Australian Contribution to the History of the Pneumoconioses}

with both silicosis and tuberculosis; the graphical representation of the findings is impressive (Figure 3). For the first time, radiological diagnosis had been independently 'validated' in terms of function. Nelson correctly appraised the relationship which should exist between radiographic and spirometric investigations; the X-ray could not, for example, diagnose bronchitis, whilst spirometry provided information additional to the X-ray on 'aerating capacity' in cases of silicosis. The two methods should be 'linked ... . in assessing damage to the lungs in compensation claims.' Forty years later this point was still not fully understood in many quarters.

An example of an important investigation yielding results of considerable practical value at the time, but of limited value epidemiologically and hence to the historian, is the Report of the Technical Committee of Inquiry to Investigate the Prevalence of Silicosis and Tuberculosis among Stone Masons, Quarrymen, Sewer Miners and Rock Choppers, Sydney, 1924. Of the 716 employees examined, 123 were found to show signs of silicosis, but no indication is given of the total population at risk, nor of the means by which the 716 were selected for examination. The only hint of a proper appreciation of epidemiological principles is the statement 'although a medical examination was not made of all the men engaged in these industries, on taking into account the number examined and after considering their distribution in groups according to age and period of time worked, the committee is convinced that a reasonably close approximation to the incidence [sic] of the disease in these industries can be made'. This is, of course, an unacceptable proposition in the absence of specific evidence to support it. Again, the lesson of this and many earlier investigations has still to be fully appreciated, in that superficial surveys, inadequately designed and conducted epidemiologically, are not rare even today.

The study of occupational dust diseases was significantly advanced, not only in Australia but also internationally, by the work of Charles Badham (1884-1943), the first Director of the Division of Industrial Hygiene in New South Wales, and greatgrandson of the Charles Badham who first used the term 'chronic bronchitis'. Badham's contributions, which ranged over a wide field, cannot be examined in detail in this paper. Perhaps his major work, in collaboration with H. B. Taylor, was on the pathology and chemical composition of the lungs of coal and metalliferous miners, and of workers exposed to other siliceous dusts (Badham and Taylor, 1933, 1938). They drew attention to the relatively low free silica content of coalworkers' lungs, indicating that coal dust, rather than silica or silicates, was capable of producing a genuine pneumoconiosis, a point in dispute at this period. They distinguished histologically between the lesions of coal and silica, and considered that the chief factor causing disability in coal pneumoconiosis was emphysema, attributable to fibrosis, rather than bronchitis. In this, they anticipated the later work of Jethro Gough on a problem which is still not fully resolved. To a degree, Badham might also be said to have anticipated the concept of 'mixed dust fibrosis' put forward more recently by A. I. G. McLaughlin, an Australian whose professional life has been spent in Britain.

It would be inappropriate at this time to examine post-war investigations in any detail, but mention must be made of the medical research conducted under the auspices of the New South Wales Joint Coal Board. W. E. George, the Board's first chief medical officer, was the first in Australia deliberately to select a random sample 


\section{Bryan Gandevia}

of an occupational population for study (George and Wallman, 1949). The sampling method, perhaps not strictly acceptable as random, but nonetheless an original and reasonable approach, was to examine all men whose surnames began with the letters C, O, A and L; this gave a 10 per cent sample of the 16,000 miners employed on the coalfields. Special value also attaches to their work today because, recognizing the difficulties of diagnosis of chronic bronchitis and of evaluating and assigning a cause to disability, they recorded the prevalence of individual symptoms. As Outhred (1967; see also Joint Coal Board, 1962) has shown, it thus becomes possible to relate effectively the earlier findings to those of current investigations, in which chronic bronchitis assumes increasing importance. George and Wallman were also emphatic on the need for autopsies on miners by pathologists 'especially interested in the solution of these problems'. This far-sighted policy has enabled the eventual integration of clinical, functional and pathological data by the Board's present medical officers to provide most significant evidence on the relevance of chronic bronchitis to disability in coalminers (McKenzie, Glick and Outhred, 1969).

\section{CONCLUSION}

This partial review illustrates not only the volume and, in general, the character of Australian research on the dust diseases over half a century but also the change from a traditional clinical approach to one based on sound epidemiological principles. Vital though it is, the change should not be viewed as a radical change in concept, but rather as an evolutionary change in technique; the modern study of the epidemiology of chronic disease is essentially the disciplined and scientific use of clinical methods in a context, not of selected patients, but of 'the people' (demos).

Today the classical pneumoconioses are much less of a problem than they were; research such as that described has made these diseases understandable and preventable. Nonetheless, it is pertinent to recall them at the present time, and to review the ways in which the requisite knowledge and control were achieved, for today's technology has new hazards and new diseases which require another reorientation of our approach to the investigation and prevention of occupational respiratory hazards.

\section{ACKNOWLEDGEMENTS}

I am grateful for much generous assistance from many quarters in my search for publications and information; without it this paper could not have been written. My thanks are also due to my secretary, Mrs. Jennifer Kearney, Miss Susan Casey and the Department of Medical Illustration, University of New South Wales.

\section{REFERENCES}

BADHAM, C., and TAYLOR, H. B., 'Coal-miner's lung; a preliminary account of the chemical analysis and pathology of the lungs of coal miners in New South Wales', Med. $J$. Aust., 1933, 1, 511.

BADHAM, C. and TAYLOR, H. B., The Lungs of Coal, Metalliferous and Sandstone Miners and other Workers in New South Wales: Chemical Analysis and Pathology. Sydney, Government Printer, 1938.

BARretT, J. W., The Twin Ideals: An Educated Commonwealth, 2 vols., London, Lewis, 1918, vol. 1, p. 285. 


\section{The Australian Contribution to the History of the Pneumoconioses}

Cowen, B. S., 'Tuberculosis in a mining community', Intercol. Med. J. Australasia, 1902, 7, 432.

Cumpston, A., 'Health and disease in the Broken Hill mining industry', in Broken Hill Mines, ed. M. Radmanovitch and J. T. Woodcock, Melbourne, 1968, p. 537.

Cumpston, J. H. L., 'Tuberculosis in Australia', Med. J. Aust., 1931, 2, 153.

Cumpston, J. H. L., 'Statistical review of tuberculosis in Australia', Trans. Aust. med. Congr. (B.M.A.), 1923, First Session, p. 237.

Fletcher, C. M., 'Pneumoconiosis of coal miners', Br. med. J., 1948, i, 1015 and 1065.

George, W. E., 'The pneumoconiosis of New South Wales coal workers', in Coal in Australia, Melbourne, Australasian Institute of Mining and Metallurgy, 1953, p. 320.

George, W. W. and Wallman, L. S., A Medical Examination of Employees of the Coal Mining Industry of New South Wales, Sydney, Joint Coal Board, 1949.

Grson, J. C. and Hugh-Jones, P., Lung Function in Coalworkers' Pneumoconiosis, M.R.C. Spec. Rep. Ser. No. 290, London, H.M.S.O., 1955.

Holmes, M. J., 'Tuberculosis in Australia', Med. J. Aust., 1937, $2,813$.

Holster, A., Exhibition of Contributions to the Literature on Pneumoconiosis by Australian Authors: Catalogue, Sydney, Royal Australasian College of Physicians, 1970.

HunTER, D., The Diseases of Occupations, London, English University Press, 1955, p. 891 et seq.

Joint Coal Board: Pneumoconiosis Statistics 1962: New South Wales Coal Industry, Sydney, 1962.

MCKenzIe, H. I., GuICK, M. and OUTHRED, K. S., 'Chronic bronchitis in coal miners: ante-mortem/post-mortem comparisons', Thorax, 1969, $24,527$.

MeIKLlejohn, A., 'History of lung diseases of coal miners in Great Britain; Part II, 18751920', Br. J. indus. Med., 1952, 9, 93; 'Part III, 1920-1952', 1952, 9, 208.

MOORE, K. R., 'Silicosis in Australia', in Records of the International Silicosis Conference, Geneva 1930, Geneva, International Labour Office, 1930.

Nelson, W. T., Report on an Investigation of the Pulmonary Condition of Mine Employees, Western Australia . . . 1925-26, Service Publication No. 5, Division of Industrial Hygiene, Commonwealth Department of Health, Canberra, 1926.

ORENSTEIN, A. J., 'The history of pneumoconiosis: A brief review', Sth Afr. med. J., 1957, 31, 797.

OUTHRED, K., 'Chronic Obstructive Lung Disease in New South Wales Coal Miners', roneoed typescript, 1967.

Summons, W., Miner's Phthisis: Reports of an Investigation at Bendigo into the Prevalence, Nature, Causes and Prevention of Miners' Phthisis, and the Ventilation of the Bendigo Mines, Melbourne, Stillwell, 1907. (These two are usually seen bound together with the above title, but they were probably originally issued separately in 1907 and 1906 respectively.)

Thomas, B. and GandeviA, B., 'Dr. Francis Workman, emigrant, and the history of taking the cure for consumption in the Australian Colonies', Med. J. Aust., 1959, $1,1$.

\section{ADDENDUM}

This paper is based on a paper read at a symposium held in the Department of Medical History, University of Melbourne, 21-23 May 1970. Since it was written, some additional references prior to 1900 to respiratory problems in miners have been identified and the bibliography extended. For some discussion of this material, see B. Gandevia 'Occupation and disease in Australia since 1788', Bull. Post-Grad. Cttee Med., Univ. Syd., 1971, 27, 157 and 199, and especially 200-201 and related notes and references. 